\title{
DÜBLIN
}

Technological University Dublin

ARROW@TU Dublin

2018-4

\section{Study of Mm-wave Microstrip Patch Array on Curved Substrate}

\author{
Zeeshan Ahmed \\ Technological University Dublin, d16127520@mydit.ie \\ Kansheng Yang \\ Technological University Dublin \\ Patrick McEvoy \\ Technological University Dublin, patrick.mcevoy@tudublin.ie
}

See next page for additional authors

Follow this and additional works at: https://arrow.tudublin.ie/engscheleart

Part of the Electrical and Electronics Commons

\section{Recommended Citation}

Ahmed, A., Yang, K., McEvoy, P. \& Ammann, Max. (2017). Study of mm-wave microstrip patch array on curved substrate. Loughborough Antenna and Propagation Conference 2017 (LAPC '17), Loughborough, United Kingdom, November 13 -14.

This Conference Paper is brought to you for free and open access by the School of Electrical and Electronic Engineering at ARROW@TU Dublin. It has been accepted for inclusion in Conference papers by an authorized administrator of ARROW@TU Dublin. For more information, please contact arrow.admin@tudublin.ie, aisling.coyne@tudublin.ie, gerard.connolly@tudublin.ie. Funder: CONNECT - Science Foundation Ireland

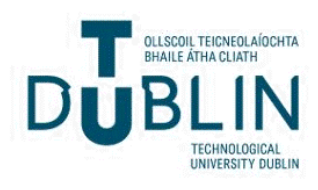


Authors

Zeeshan Ahmed, Kansheng Yang, Patrick McEvoy, and Max Ammann

This conference paper is available at ARROW@TU Dublin: https://arrow.tudublin.ie/engscheleart/269 


\title{
Study of mm-Wave Microstrip Patch Array on Curved Substrate
}

\author{
Zeeshan Ahmed, Kansheng Yang, Patrick McEvoy, Max J. Ammann \\ Antenna \& High Frequency Research Centre (AHFR), Dublin Institute of Technology, Dublin, Ireland. \\ zeeshan.ahmed@mydit.ie,kansheng.yang@mydit.ie,patrick.mcevoy@dit.ie,max.ammann@dit.ie
}

Keywords: 5G; millimetre wave; array; microstrip; curving.

\begin{abstract}
A millimetre wave rectangular microstrip patch antenna array for fifth generation communications (5G) applications is presented. With the increase in demand for high data rates and capacity, there is a need to include $\mathrm{mm}$-Wave frequencies for $5 \mathrm{G}$. The $4 \times 2$ patch array is simulated and fabricated on a Rogers RT/Duroid 5880 substrate with a thickness of $0.25 \mathrm{~mm}$. The effects of bending the substrate on the antenna performance are also presented. The experimental results show a fractional bandwidth and gain of more than $3 \%$ and $16.1 \mathrm{dBi}$, respectively.
\end{abstract}

\section{Introduction}

The expansion of the wireless industry around the globe has enabled people to access the internet and the demand for high-quality wireless communications systems is growing exponentially. This rapid growth demands for high data rates and overcoming challenges including capacity issues to accommodate more users and applications which require quick and quality research in order to develop next generation wireless communications systems. The mm-Wave spectrum is most likely to be the potential candidate to implement the $5 \mathrm{G}$ communication applications because of its huge bandwidth [1].

The antenna is an essential component of wireless communication system because of its effects on the receiver's sensitivity. The introduction of the mm-wave band for $5 \mathrm{G}$ applications has brought considerable attention to the researchers in order to analyse and design antennas which are reported in several papers [4-7]. In [2], a multi-band split ring resonator was proposed which covers $6 \mathrm{GHz}$ band which is also expected for $5 \mathrm{G}$ communications [3]. A $4 \times 1$ and $2 \times 2$ stacked patch array on LTCC and PCB substrates are presented in [4] with a maximum gain of $13 \mathrm{dBi}$. Other works include dielectric superstrate and EBG ground structure to improve radiation characteristics in 5G [5] and phased arrays [6]. A review for several $5 \mathrm{G}$ antennas was presented in [7].

In this paper, a $4 \times 2$ microstrip array with rear feeding has been presented. The spacing between the elements plays a key role in the resonant frequency and the performance (gain and efficiency) of the antenna. The effects of mechanically curving the substrate on the antenna's performance have also been presented in section 4 of this paper. A study of a UWB directional antenna placed conformally on a cylindrical pipe section was reported in [8]. For realistic results, the edgefeeding mechanism is adopted for the curved substrate and results for concave and convex bending are noticed.

\section{Antenna Geometry}

The geometry of the proposed microstrip patch antenna array for $5 \mathrm{G}$ communications is shown in Figure 1. The array is designed on a flexible Rogers RT/Duroid 5880 substrate with relative permittivity of 2.2 , loss tangent of 0.0009 and thickness of $0.25 \mathrm{~mm}$ having dimensions $19 \times 30 \mathrm{~mm}^{2}$. The array consists of 8 elements with a spacing of $0.75 \lambda$ between the row elements. Each patch is connected to a 100 line and then to a matching arrangement using quarter wave transformers. The $90^{\circ}$ bends are mitred. The two rows of the array are connected through a one wavelength network including two-quarter wave transformers and a 50 pad to which the connector is soldered from the bottom through a $0.5 \mathrm{~mm}$ via hole. The proposed antenna is simulated using CST Microwave Studio Suite 2016 with a 50 modelled SMK (Sub-Miniature version K) connector. Table 1 shows the design parameters of the antenna in detail.

\begin{tabular}{|l|l|l|l|}
\hline Parameter & $\begin{array}{c}\text { Dimension } \\
(\mathrm{mm})\end{array}$ & Parameter & $\begin{array}{c}\text { Dimension } \\
(\mathrm{mm})\end{array}$ \\
\hline$W s$ & 30.0 & $L s$ & 19.0 \\
\hline$W p$ & 4.48 & $L p$ & 3.55 \\
\hline$W i$ & 1.10 & $L i$ & 0.20 \\
\hline$W q$ & 0.48 & $L q$ & 1.99 \\
\hline$W f$ & 0.8 & $L f$ & 2.30 \\
\hline$W 100$ & 0.25 & $L 100$ & 1.11 \\
\hline$d$ & 1.52 & $x$ & 8.10 \\
\hline
\end{tabular}

Table 1 Design parameters of the proposed antenna array

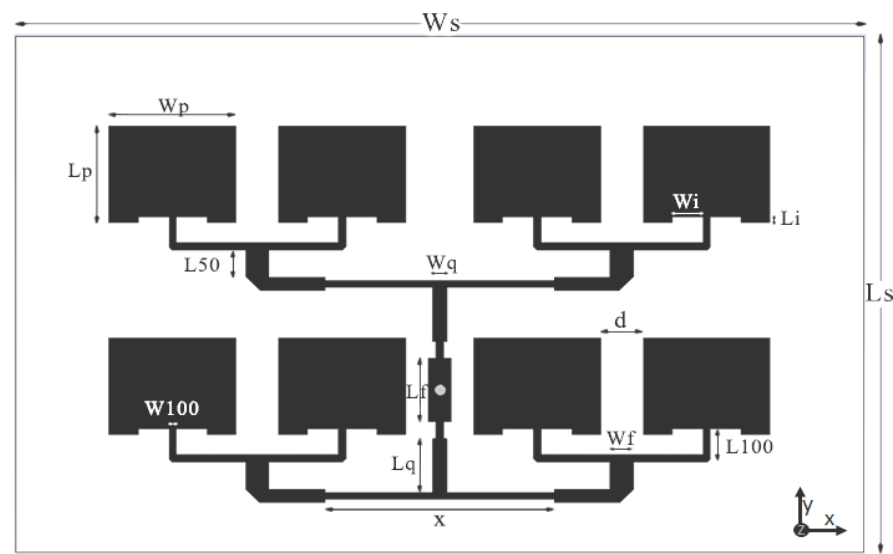

Fig. 1 The geometry of $4 \times 2$ element rear-fed array 


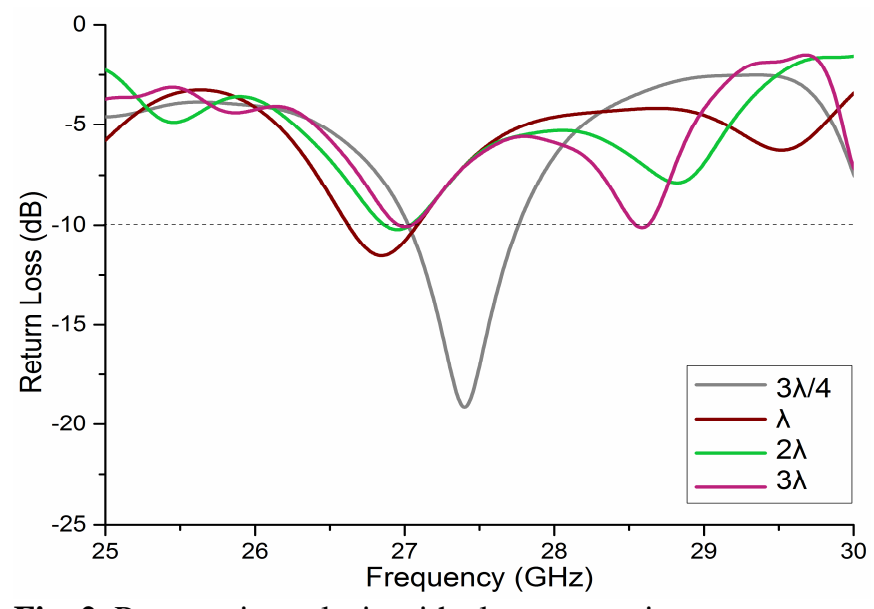

Fig. 2 Parametric analysis with element spacing

\section{Modelling, Parametric Analysis and Results}

In order to achieve high gain results, the single patch antenna was first simulated and optimised at $27.4 \mathrm{GHz}$ for best matching. The addition of an inset feed improves the impedance matching and minimises the input reactance of the antenna. The gain of the single patch antenna was found to be $7.5 \mathrm{dBi}$.

The effects of spacing between the patch elements in the array were optimised accordingly. Figure 2 shows the effect on the S11 for different element spacing. The frequency response tunes down and the bandwidth decreases as the spacing between the elements increases from $0.75 \lambda$ to $3 \lambda$. The increase in the distance also results in impedance mismatching. From $\lambda$ to $3 \lambda$, in the $28 \mathrm{GHz}$ range, there are additional resonances observed.

Figure 3 shows the measured and simulated S11 for the antenna array. The antenna array is measured using Rhode and Schwarz Vector Network Analyzer (ZVA40) and shows good agreement with the simulated results. The simulated results show that the antenna has $|\mathrm{S} 11|<-10 \mathrm{~dB}$ between $27.04 \mathrm{GHz}$ and $27.71 \mathrm{GHz}$ centred at $27.4 \mathrm{GHz}$ with a fractional bandwidth of $2.44 \%$. The measured results show that the antenna is operating between $26.97 \mathrm{GHz}$ and $27.82 \mathrm{GHz}$ with a minimum value of $\mathrm{S} 11$ at $27.4 \mathrm{GHz}$.

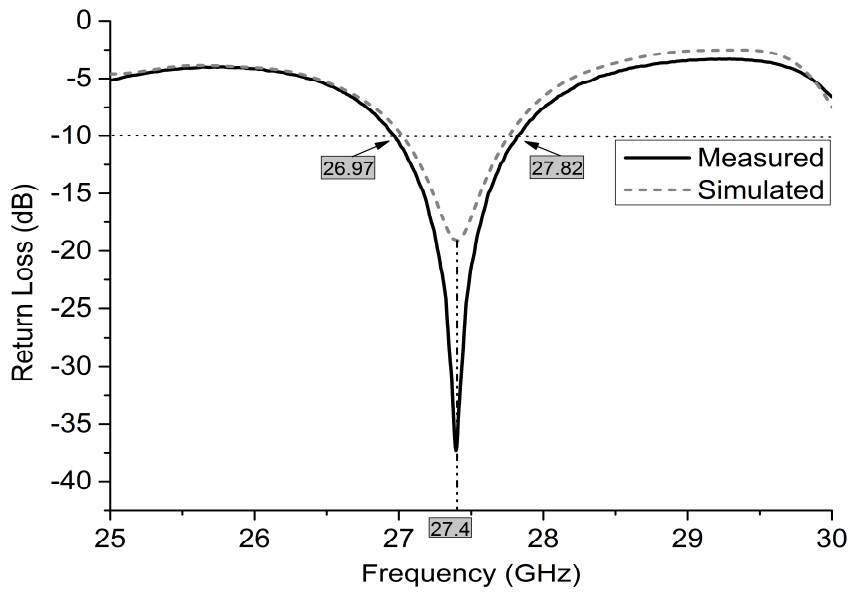

Fig. 3 Simulated and measured S11 at $27.4 \mathrm{GHz}$

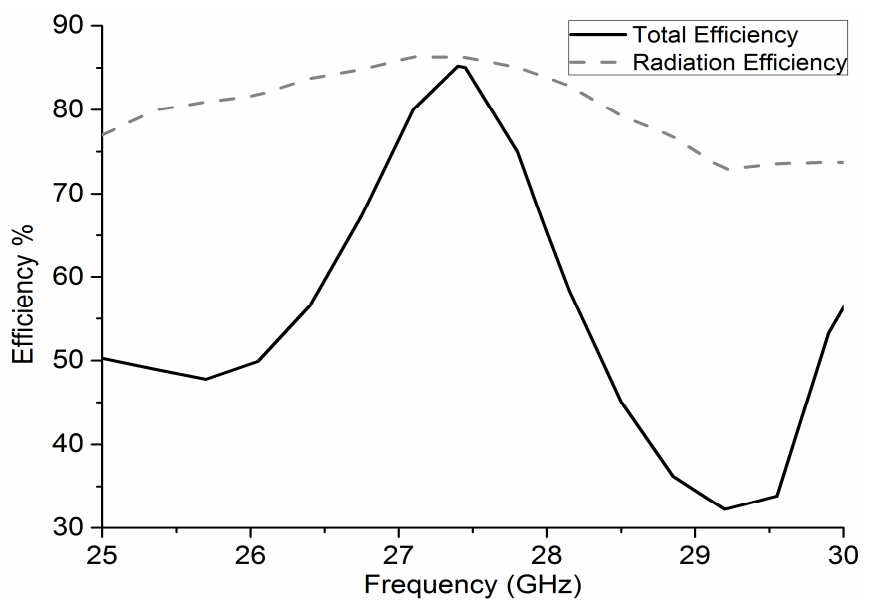

Fig. 4 Total and radiation efficiency

The measured fractional bandwidth is more than $3.1 \%$.

The radiation and total efficiencies of the array are presented in Figure 4. At $27.4 \mathrm{GHz}$, the antenna has the maximum efficiency and the percentage of the power to the antenna to the power radiated from the antenna is more than $85 \%$. The $90^{\circ}$ mitring helps to improve the efficiency of the antenna by $4 \%$.

Figure 5 shows the measured and simulated gain of the array antenna. From the figure, it can be seen that the array has a high measured gain between $25 \mathrm{GHz}$ and $29 \mathrm{GHz}$ with a peak gain of $16.1 \mathrm{dBi}$ at $27.4 \mathrm{GHz}$. The simulated gain at $27.4 \mathrm{GHz}$ is $15.7 \mathrm{dBi}$. The feeding network is optimised in such a way that the feeding arrangement and the power divider network constitute to only $0.4 \mathrm{dBi}$ attenuation of the total gain.

The simulated and measured radiation pattern plots are shown in Figure 6. Figure 6(a) shows the results in the yz-plane (E-Plane). The radiation pattern is tested in an anechoic chamber. The antenna has a directive radiation pattern with a half power beamwidth (HPBW) of $35^{\circ}$ in yz-plane and $20^{\circ}$ in xz-plane. It further verifies the peak gain at $27.4 \mathrm{GHz}$ to be $16.1 \mathrm{dBi}$. The squint visible in the yz-plane of the rear-fed antenna array is most likely a result of the addition of quarterwave transformers or microstrip lines [9]. Figure 6(b) shows the polar plot for xz-plane (H-plane) of the antenna. The measured and simulated results are in good agreement.

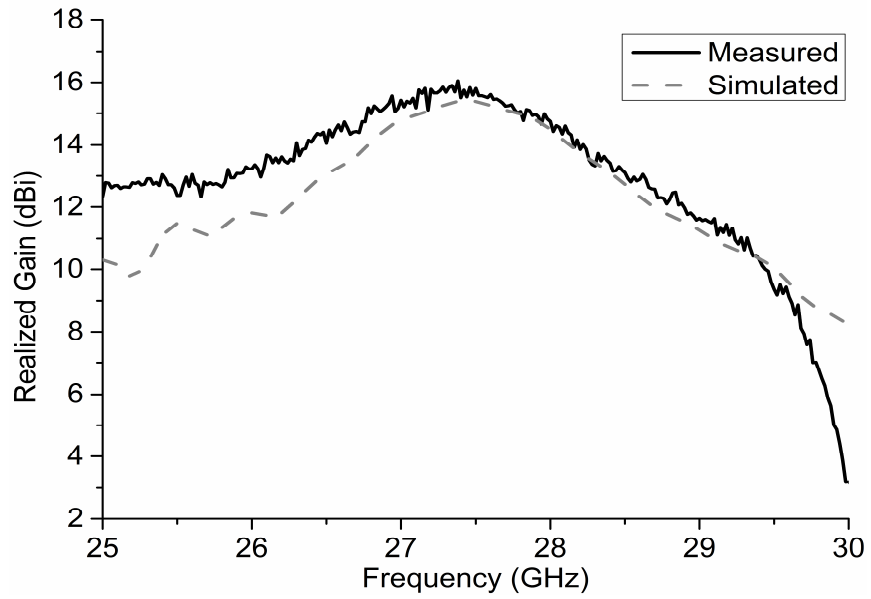

Fig. 5 Simulated and measured gain for the $4 \times 2$ array 


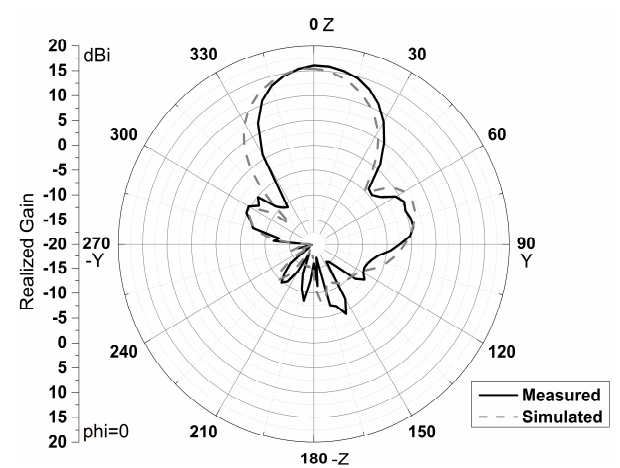

(a)

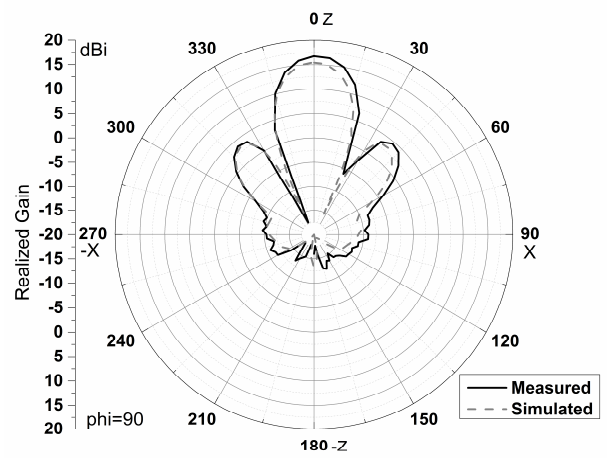

(b)

Fig. 6 Measured and simulated radiation patterns (a) yz-plane (b) xz-plane

\section{Curved Substrate: Modelling and Results}

The effects of mechanically curving the substrate on matching and radiation properties were studied to determine tolerances. With the configuration shown in Figure 1, it is not realistically possible to curve the substrate because of the soldered connector at the bottom of the antenna. However, some arrays may have edge fed connectors and an array shown in Figure 7 was prototyped and tested. In place of the feed line connecting the two rows of the array shown in Figure 1, a 50 line is introduced which connects the two rows with a one wavelength line and extends to the edge of the substrate. The edges of the line are tapered to avoid shortening the connector. The dimensions of this antenna are $23 \times 30 \mathrm{~mm}^{2}$. The rest of the configurations are same as in Figure 1.

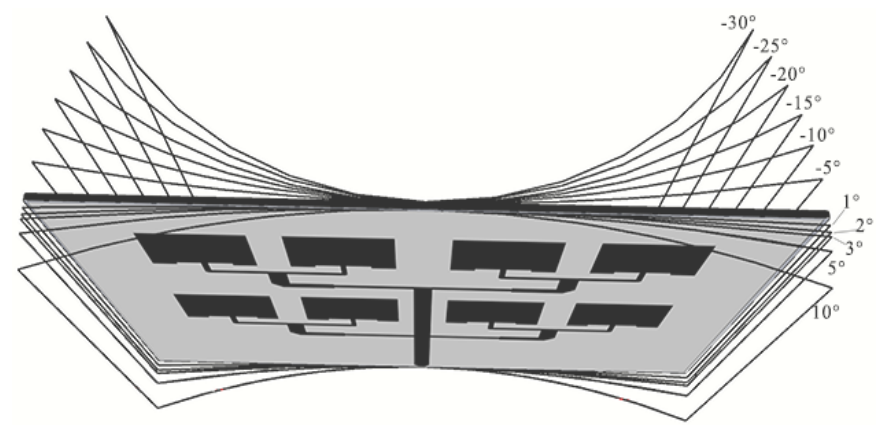

Fig. 7 Geometry of the curved substrate edge-fed antenna
Figure 8 shows the effects of concave and convex bending of the substrate on the S11. From the graph, it can be noticed that there are minute resonant frequency shifts with the concave curving but there is little change in bandwidth. The impedance mismatching increases with the increase in concave bending. On the other hand, the frequency tunes higher than the reference $27.4 \mathrm{GHz}$ when the antenna is curved in a convex shape. At $+3^{\circ}$ bend, another resonance emerges at $25.23 \mathrm{GHz}$ and shifts to the right as the convexity increases. This is because of the increased patch mutual coupling with reduced distance between patches. Similar to concave bending, the antenna impedance matching degrades with increased curve angle but little changes are observed in the bandwidth.

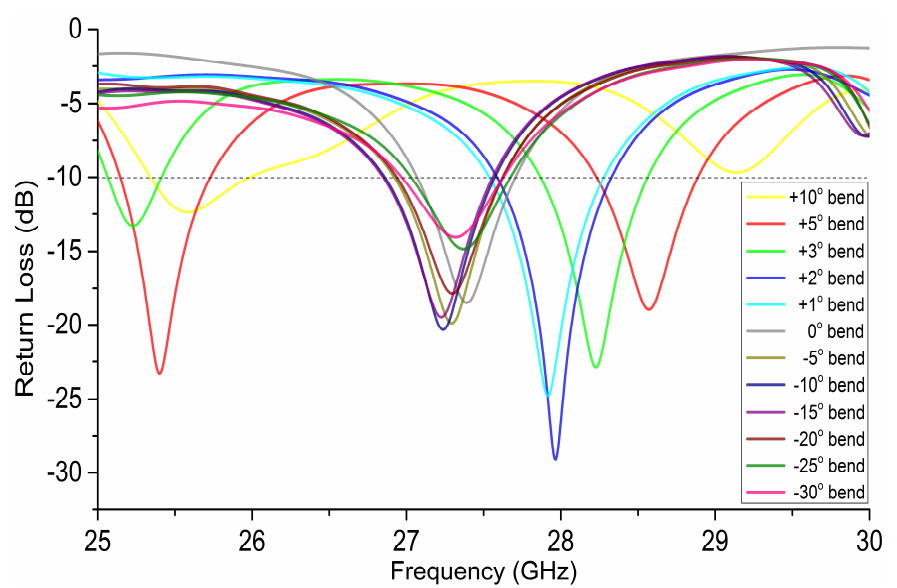

Fig. 8 Simulated S11 with concave and convex bending

Figure 9 shows the gain plot of the array on curved substrate. With reference to the gain for $0^{\circ}$ bending, the gain does not vary much with the concave bending. The antenna gain profile for $25-30 \mathrm{GHz}$ is persistent and maximum variation in peak gain is $1 \mathrm{dBi}$ for bending from $0^{\circ}$ to $-30^{\circ}$ (concave). The gain profile changes for convex bending greater than $0^{\circ}$. Although the peak gain is stable with this design, it tunes up in frequency with convex bending.

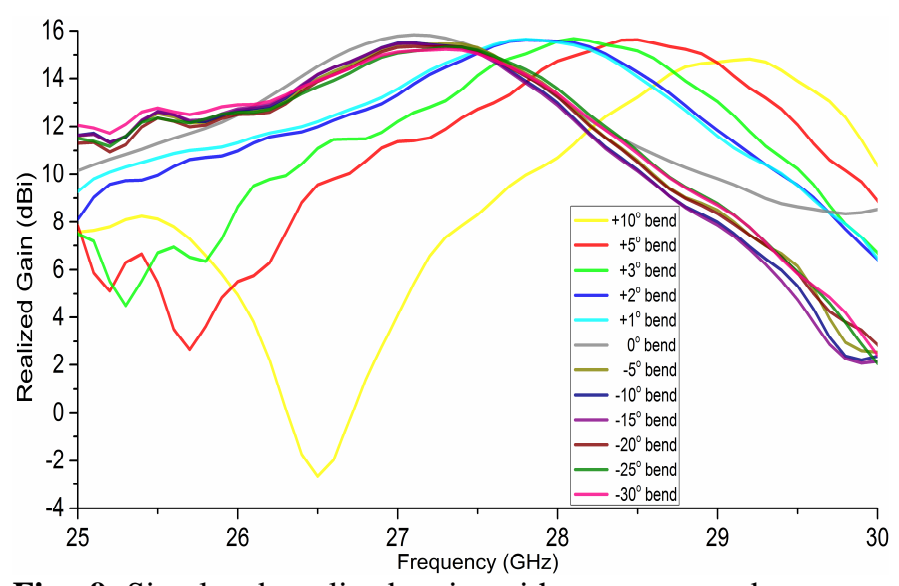

Fig. 9 Simulated realized gain with concave and convex bending 


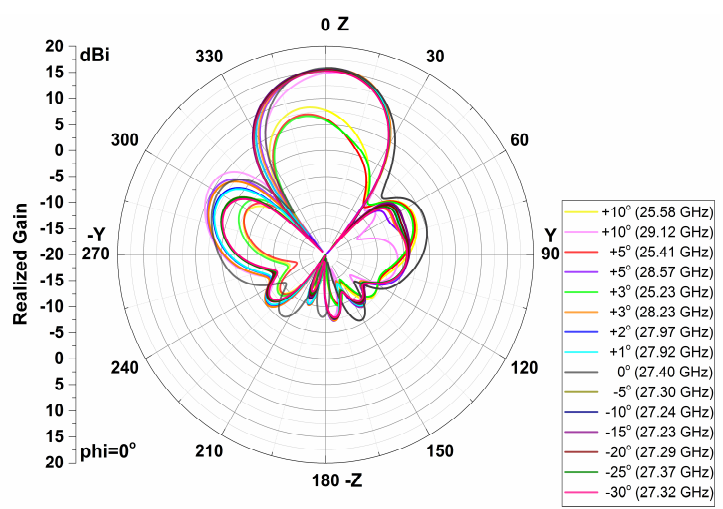

(a)

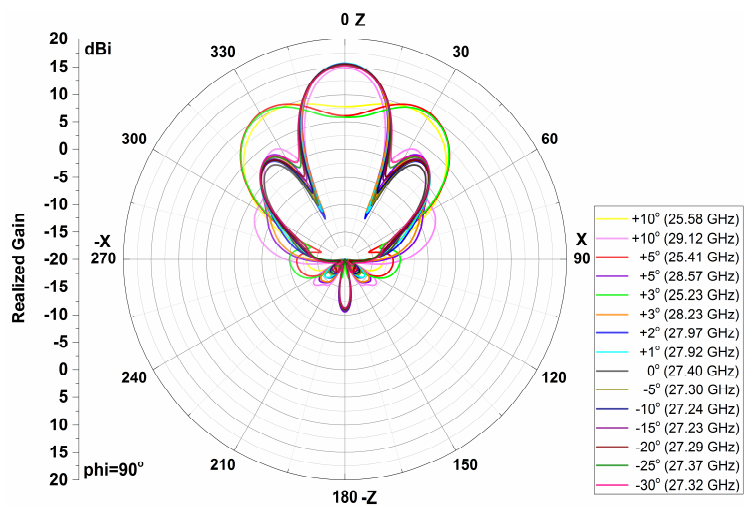

(b)

Fig. 10 Polar plots with curved substrate (a) yz-plane (b) xz-plane

The 2-D polar plots on the curved substrate are shown in Figure 10. Figure 10(a) shows the pattern for the yz-plane of the antenna. It can be seen in the figure that the increase in the concave angle does not affect the overall gain pattern but has small variations in the gain. The plots of additional resonances with convex bending can be seen distinctly with reduced gain. The xz-plane in Fig. 10(b) clearly shows the main lobe splits at $3^{\circ}$ for $25.23 \mathrm{GHz}$, which is the additional resonance. The increase in bending in concave direction increases the side lobe level, which leads to a wider beamwidth but reduced gain. The prototyped antenna is shown in Figure 11.

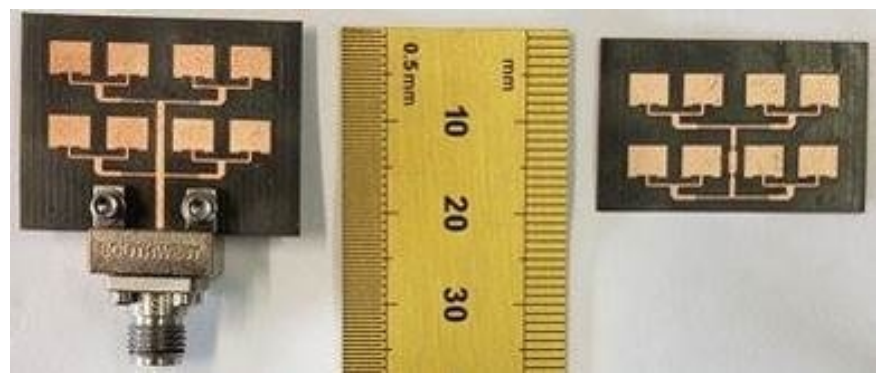

Fig. 11 Prototype of the proposed antennas

\section{Conclusion}

A $4 \times 2$ element microstrip antenna array of dimension $19 \times 30 \times 0.25 \mathrm{~mm}^{3}$ for $5 \mathrm{G}$, providing a $16.1 \mathrm{dBi}$ peak gain, is described. The antenna is analysed with rear probe feed and edge feed arrangements. The effects of substrate concave and convex bending are investigated using the edge feed. Concave curving of the substrate was found to have minimal effect whereas performance is shown to be heavily dependent on convex curve angle.

\section{Acknowledgements}

This publication has emanated from research conducted with the financial support of Science Foundation Ireland (SFI) and is co-funded under the European Regional Development Fund under Grant Number 13/RC/2077.

\section{References}

[1] T. S. Rappaport et al. "Millimeter Wave Mobile Communications for 5G Cellular: It Will Work!", IEEE Access, volume 1, pp. 335-349, (2013).

[2] M. K. Ishfaq, T. A. Rahman, H. T. Chattha, M. U. Rehman. "Multiband Split-Ring Resonator Based Planar Inverted-F Antenna for 5G Applications", International Journal of Antennas and Propagation, volume 2017, (2017).

[3] Ofcom. "Spectrum above $6 \mathrm{GHz}$ for Future Mobile Communications", Ofcom, London, UK, (2015). Available: https://www.ofcom.org.uk/_data/assets/pdf_ file/0023/69422/spectrum_above_6_ghz_cfi.pdf

[4] K. S. Chin, H. T. Chang, J. A. Liu, H. C. Chiu, J. S. Fu, S. H. Chao. "28-GHz Patch Antenna Arrays with PCB and LTCC Substrates", Proceedings of 2011 Cross Strait Quad-Regional Radio Science and Wireless Technology Conference, Harbin, pp. 355-358, (2017).

[5] O. M. Haraz, A. Elboushi, S. A. Alshebeili and A. R. Sebak. "Dense Dielectric Patch Array Antenna With Improved Radiation Characteristics Using EBG Ground Structure and Dielectric Superstrate for Future 5G Cellular Networks", IEEE Access, volume 2, pp. 909913, (2014).

[6] M. Khalily, R. Tafazolli, T. A. Rahman and M. R. Kamarudin. "Design of Phased Arrays of Series-Fed Patch Antennas With Reduced Number of the Controllers for 28-GHz mm-Wave Applications", IEEE Antennas and Wireless Propagation Letters, volume 15, pp. 1305-1308, (2016).

[7] M. A. Matin. "Review on Millimeter Wave AntennasPotential Candidate for 5G Enabled Applications", Advanced Electromagnetics, volume 5(3), pp. 98-105, (2016).

[8] D. Gaetano, M. J. Ammann, P. McEvoy, M. John, L. Keating, and F. Horgan. "Proximity study of a conformal UWB directional antenna on water pipe", Microwave and Optical Technology Letters, volume 54(8), pp. 1982-1986, (2012).

[9] A. Narbudowicz, M. J. Ammann, and D. Heberling. "On pattern reconfigurable antennas steered by modulation scheme", 9th IEEE European Conference on Antennas and Propagation (EuCAP), (2015). 